\title{
O PROGRAMA MICROEMPREENDEDOR INDIVIDUAL: UMA ALTERNATIVA PARA REDUÇÃO DO EMPREGO INFORMAL
}

\section{THE MICROEMPREENDEDOR INDIVIDUAL PROGRAM: AN ALTERNATIVE TO REDUCING INFORMAL EMPLOYMENT}

\author{
Dênis Mateus de Paiva ${ }^{1}$ \\ José Cláudio Pereira ${ }^{2}$ \\ Paulo Henrique Dias Pereira ${ }^{3}$ \\ João Victor Guedes Neto ${ }^{4}$ \\ Leandro Tavares dos Santos ${ }^{5}$
}

\section{RESUMO}

Este artigo objetiva apresentar o programa Microempreendedor Individual (MEI) como uma alternativa para redução da incidência do emprego informal no Brasil, apontando-a como um mecanismo viável para o aumento do número de trabalhadores legalizados juntos às autoridades governamentais. $\mathrm{O}$ trabalho foi desenvolvido utilizando-se dois métodos de pesquisa: documental e bibliográfico, fazendo uso de publicações oficiais do governo e de especialistas no assunto em livros e periódicos, além de resultados de pesquisa do Serviço Brasileiro de Apoio às Micro e Pequenas Empresas (SEBRAE). Percebeu-se que o MEI oferece aos interessados vantagens consideráveis que motivam os trabalhadores a procurarem a formalização da sua situação profissional, vislumbrando a possibilidade de obter os mesmos benefícios dos demais e oportunidades que a informalidade não thes proporciona, bem como o acesso à Previdência e a possibilidade de expandir seu empreendimento.

Palavras-Chave: Informalidade. Desenvolvimento. Simples Nacional. Empreendedor. Microempreendedor Individual.

\begin{abstract}
This paper aims to present the Microempreendedor Individual (MEI) program as an alternative to reducing informal employment in Brazil, pointing it out as a feasible mechanism to increase the number of workers legalized with the government authorities. This work was developed by making use of two research methods: documenting and bibliography, whereas official documents and specialists' researches in books and journals were linked to results found by the Serviço Brasileiro de Apoio às Micro e Pequenas Empresas (SEBRAE). It was noted that the MEI offers advantages that motivate workers to look for legalizing their professional activities, looking for the possibility of obtaining the equal
\end{abstract}

\footnotetext{
${ }^{1}$ Mestrando em Economia pela Universidade Federal da Bahia. Email: paivadenis@yahoo.com.br.

${ }^{2}$ Doutor em Educação, Administração e Comunicação pela Universidade São Marcos, UNIMARCO. Professor Titular e Emérito da FAI - Centro de Ensino Superior em Gestão, Tecnologia e Educação. Email: jclaudio@fai-mg.br

${ }^{3}$ Mestrando em Economia Aplicada do Departamento de Economia Rural da Universidade Federal de Viçosa. Email: phdpereira@yahoo.com.br

${ }^{4}$ Mestrando em Gestão Pública e Sociedade pela Universidade Federal de Alfenas. Email: contato@joaovictorguedes.com.br

${ }^{5}$ Mestrado em Desenvolvimento Regional e Urbano, pela Universidade Salvador. Email: leandrotsantos@yahoo.com.br
} 
benefits as the already registered workers, as access to social security and chances of expanding their businesses.

Keywords: Informality. Development. Simples Nacional. Entrepreneur. Individual Microenterprise.

\section{Considerações Iniciais}

Nos últimos anos, o Brasil vem se destacando no cenário internacional como um país de futuro promissor, uma das potências emergentes que irá compor a nova ordem geopolítica mundial, devido ao seu crescimento rápido e à alta capacidade de se recuperar frente às grandes crises mundiais, como a crise imobiliária americana e a crise monetária da zona do Euro. Esse cenário positivo contribuiu para que as altas taxas de desemprego, verificadas nas décadas passadas, se reduzissem de forma considerável, gerando bons indicadores econômicos e também um sério problema: o aumento do emprego informal.

Os trabalhadores informais são desamparados em relação às leis que regem os contratos trabalhistas e são privados de benefícios concedidos aos seus semelhantes formalizados como o Fundo de Garantia do Tempo de Serviço (FGTS) e o Seguro Desemprego, tornando-se agentes instáveis em um mercado competitivo que, dada a incerteza do sucesso, correm grandes riscos de médio e longo prazo ao desenvolver seus próprios empreendimentos. Visando contornar a situação, o governo buscou algumas soluções, dentre as quais encontra-se o programa Microempreendedor Individual (MEI), instituído por meio da Lei Complementar número 128/08, que será tratada neste trabalho. O MEI é um programa abrangido pelo Simples Nacional e seu principal objetivo é possibilitar a formalização de trabalhadores dos mais diversos ramos de atuação.

Esta pesquisa tem como objetivo apresentar o MEI como alternativa para formalizar a atividade do trabalhador, possibilitando a ele o acesso aos benefícios comuns garantidos aos trabalhadores formalizados junto às autoridades legais e, por meio destes, reduzindo sua instabilidade perante aos resultados garantidos pelo mercado e, ainda, aumentando a receita da máquina estatal para que, por meio da tributação adicional, seja possível realizar novos investimentos rumo à maximização do desenvolvimento.
Faz-se relevante a apresentação de novas ideias que venham a oferecer contribuição significativa para colaborar com a redução do emprego informal no país. Neste trabalho o MEI será apresentado como uma dessas possíveis escolhas viáveis, tanto por parte do Estado como por parte dos trabalhadores.

O estudo será desenvolvido utilizando-se do método de pesquisa bibliográfica, fazendo uso de publicações de especialistas no assunto em livros e periódicos, além de material divulgado por fontes oficiais do governo em suas diversas esferas e também do Serviço Brasileiro de Apoio às Micro e Pequenas (SEBRAE), caracterizando-se, nesse caso, também como pesquisa documental.

Para melhor compreensão da mensagem que se deseja levar, o artigo foi dividido em partes. Primeiramente será feita uma introdução mostrando o contexto atual de crescimento econômico nacional, chegando ao ponto em que o emprego informal começa a crescer. Em seguida, será abordado o Simples Nacional, um sistema de tributação simplificada formulado com o intuito de facilitar o recolhimento de contribuições das Microempresas e das Empresas de Pequeno Porte, fator este de fundamental importância para o entendimento do que representa o MEI dentro do contexto empresarial. Feita essa abordagem, será exposto o MEI e suas especificações, aspectos legais e possibilidades de adequação, visando conter o aumento do emprego informal no Brasil.

\section{Informalidade e crescimento do país}

Este tópico abordará alguns dos aspectos relativos ao crescimento econômico do Brasil e as consequências trazidas pelos gargalos deixados pela falta de planejamento governamental. Paralelamente ao avanço de diversos setores da economia ocorreu o crescimento do desemprego e a consequente migração de parte da população atingida por esse fato para o emprego informal. 


\subsection{Cenário de desenvolvimento econômico favorável}

Nos últimos anos, o Brasil vive cercado de expectativas quanto a sua capacidade de crescimento econômico, sendo considerado por muitos órgãos internacionais e especialistas da área uma potência emergente, com um papel futuro decisivo frente à nova ordem global. As perspectivas são confirmadas quando se observa a evolução do crescimento do Produto Interno Bruto (PIB) do país na última década, que veio acompanhado de melhora em várias áreas, como a balança comercial e a geração de empregos. Esses indicadores são superiores aos de muitos países desenvolvidos, e são ainda maiores em relação aos índices do próprio país na década passada, conforme divulgado pelo Itamaraty (BRASIL, 2011a).

O progresso do país em diversos setores teve seu princípio muito provavelmente no período pósditadura militar e segue até hoje, acompanhado de vários fatores positivos como a descoberta do présal, o avanço do etanol pelos mercados internacionais e a inclusão do país em um novo agrupamento chamado de BRIC (Brasil, Rússia, Índia e China), termo cunhado por Jim O'Neill, economista-chefe da Goldman Sachs, no estudo intitulado "Building Better Global EconomicBRICS" (HURRELL, 2009). Posteriormente, em 13 de abril de 2011, o termo conhecido como BRIC passou a ser conhecido por BRICS, devido a inclusão da África do Sul no agrupamento (BRASIL, 2011a).

No estudo de O'Neill, o autor aborda aspectos referentes ao avanço das economias desses países, tendo como parâmetros de comparação as suas situações em um passado recente e as perspectivas para o seu futuro, quando espera-se que, juntos, os países do agrupamento sejam capazes de superar os países mais desenvolvidos do mundo, integrantes do Grupo dos Sete (G7) em diversas variáveis analisadas.

Neste artigo será tratado apenas o caso brasileiro, mostrando resumidamente alguns dos fatores que evidenciam o desenvolvimento pelo qual o país passa e também uma das consequências dessa rápida expansão: o crescimento do emprego informal.

A imagem do Brasil mudou nos últimos anos frente à critica internacional, conforme foi sinalizado por Rêgo (2008). Paralelamente ao cenário positivo para o crescimento, houve a estabilização e consoli- dação do regime democrático nacional, os grandes investimentos realizados pelo Estado em desenvolvimento social, o empenho do país na organização de grandes eventos como o Pan Americano de 2007, a Copa do Mundo de 2014 e as Olimpíadas de 2016, a descoberta de novos poços de petróleo e gás, dentre outros fatores que direcionaram os olhares da opinião mundial para o Brasil.

Todos esses avanços da economia brasileira impactam, como não poderia deixar de ser, a rotina dos cidadãos comuns espalhados por todo o país. Como exemplo, cita-se um dos focos deste artigo: os trabalhadores informais. Esse tipo de trabalhador avançou em vários setores da economia, principalmente nas metrópoles brasileiras, e esse formato de vínculo torna-se prejudicial não somente ao trabalhador, que abdica de vários benefícios, mas também ao governo que deixa de arrecadar com o mesmo. Maiores reflexões sobre o processo crescente da informalidade no país serão tratadas a seguir.

\subsection{Ascensão do emprego informal no Brasil}

Vale lembrar que o emprego informal sempre teve seu espaço na economia brasileira, bastando citar como exemplo o maior centro de comércio a céu aberto da América Latina, localizado no centro da cidade de São Paulo. Na Rua 25 de Março, numerosos trabalhadores informais disputam espaço com outros informais e também junto às lojas comerciais, vendendo produtos nacionais e importados. Tendo em vista que cenários como esse já estavam impregnados na cultura brasileira, essencialmente paulistana nesse caso, antes mesmo do "boom" do crescimento brasileiro, são apresentados outros referenciais para exemplificar o problema que o emprego informal passou a representar hoje para a economia brasileira.

Em recente pesquisa realizada pelo Instituto de Pesquisa Econômica Aplicada (IPEA), foi identificado um crescimento substancial do número de trabalhadores informais logo após a promulgação da Constituição de 1988, puxado por uma série de fatores, como pode ser visualizado no trecho a seguir:

No entanto, na década de 1990, a confluência entre as transformações tecnológicas, produtivas e financeiras em nível mundial, além da desregulação e enfraquecimento das instituições que estruturavam as relações de trabalho, pressionaram o mercado de 
trabalho no sentido da redução relativa da formalização (POCHMANN et al., 2011, p.4).

O desgaste das instituições, além das mudanças pelas quais a economia nacional passou nesse período de transição foram fatores determinantes para o avanço do número de postos informais.

Segundo dados obtidos na Pesquisa Nacional por Amostra de Domicílios - PNAD (2009), realizada pelo Instituto Brasileiro de Geografia e Estatística (IBGE) - foi constatada, nos últimos anos, uma relativa oscilação dos postos de trabalho, havendo uma grande criação de postos formais. Mesmo assim, foi verificado que os postos informais ou aqueles que não contribuem com a previdência ainda representam mais de $50 \%$ da População Economicamente Ativa (PEA) atualmente.

Ainda de acordo com o mesmo estudo, a ampliação da formalização foi motivada especialmente pelo ritmo maior de criação de postos formalizados de ocupação e não por substituição dos postos informais existentes. Uma das variáveis responsáveis por impedir que as novas vagas criadas fossem informais deveu-se à recuperação do poder de fiscalização do governo e das políticas de incentivo que vêm sendo promulgadas, apesar de ainda serem insuficientes para atingir a fatia esperada de trabalhadores.

Dada a concordância dos trabalhadores em permanecer atuando na informalidade e dos empregadores em continuar com esse mesmo cenário, o resultado é uma riqueza gerada fora dos parâmetros da legalidade, fazendo com que a economia nacional desperdice recursos, crescendo menos do que poderia em relação aos outros BRICS. E para piorar, esse panorama acaba por alimentar o rombo nas contas públicas nacionais.

Entretanto, parte do problema é de responsabilidade do próprio governo. Por um lado, o excesso de tributação no país, uma das maiores no mundo, torna a informalidade altamente atrativa para os empregadores, por outro lado, com a grande variedade de benefícios oferecidos pelo Governo Federal para famílias de baixa renda, o trabalho informal também se torna atrativo para as famílias que não têm uma renda oficial, o que impediria que contassem, em paralelo, com os benefícios oferecidos pelo Estado. Por um lado, o prejuízo futuro - exemplificado pela ausência do Seguro Desemprego e da Previdência - é menosprezado por essas famílias que acreditam que sempre poderão contar com o respaldo do Estado, mesmo que permaneçam passivas e não busquem uma condição melhor, formalizando seu vínculo empregatício.

Segundo relatório produzido pela McKinsey \& Company (2004), já em meados da década passada o Brasil aparecia como segundo colocado no ranking da informalidade, perdendo somente para a Rússia, coincidentemente outro país membro dos BRICS e sétimo no ranking de maiores cobradores de alíquotas de contribuição previdenciária. Algumas dificuldades são apontadas pelos especialistas para justificar esse cenário negativo de informalidade no mercado nacional e, dentre elas, se pode citar a alta carga tributária, as leis trabalhistas ultrapassadas e o excesso de burocracia. Para superar esses problemas, seria necessário mais que a boa vontade governamental, mas uma iniciativa prática que visasse atenuar essas dificuldades, o que seria muito bem-vindo ao mercado.

Muitos trabalhadores não vinculados a algum patrão (foco principal deste trabalho) temem a formalização justamente devido a esses fatores negativos segundo pesquisa realizada pela Universidade de Brasília (UnB, 2010). Essa grande parte da população se esquiva dos impostos mesmo que tenha que abrir mão de algumas vantagens e direitos para obter uma remuneração melhor do que o mercado poderia lhe pagar. Uma alternativa que vem sendo proposta pelo governo em parceria com outros órgãos, visando a formalização dessa fatia da população, é oferecer a oportunidade para que ela possa abrir sua própria empresa, por meio do programa Microempreendedor Individual (MEI), que objetiva criar Empreendedores Individuais (EI), que seriam empresários de seus próprios negócios, pagando um pequeno valor à Previdência Social, visando o benefício de ter os mesmos direitos que um trabalhador formal e, indo um pouco além, podendo também obter alguns benefícios oferecidos aos microempresários.

Esse assunto será abordado nos próximos tópicos desse trabalho, partindo inicialmente do SIMPLES NACIONAL, de onde o projeto do MEI se origina, e sem o qual uma abordagem resumida tornaria a explicação do MEI um pouco mais complexa. 


\section{Alternativas para a redução do emprego informal}

Inicialmente, este tópico apresentará uma rápida abordagem sobre o SIMPLES NACIONAL, que é um sistema de tributação simplificada, formulado com o objetivo de facilitar o recolhimento de contribuições das empresas de menor porte, promovendo, ao mesmo tempo, a inclusão das micro e pequenas empresas no processo produtivo brasileiro. Este é também o precursor do MEI, tema central deste trabalho e que veio, por sua vez, a tornar o SIMPLES ainda mais acessível aos trabalhadores autônomos de diversos segmentos e também aos pequenos empresários que antes não se enquadravam no referido sistema de tributação.

\subsection{O Simples Nacional}

Mediante o desequilíbrio detectado no processo de concorrência entre as micro e pequenas empresas com as grandes corporações, a Constituição Federal de 1988 (Brasil, 1990), em seus artigos 170 e 179, sinalizou com a necessidade de algum tipo de medida pública para reduzir as disparidades e proporcionar aos pequenos empresários alguma chance de concorrer com as grandes empresas.

O artigo 170 demarca o tratamento diferenciado, favorável e simplificado que os micro e pequenos empresários receberão por parte do governo federal, criando um ambiente propício para o surgimento de novos empreendimentos de origem nacional. Por sua vez, o artigo 179 apresenta nada mais do que o papel exercido pelo Estado na regulação da atividade econômica, bem como o apoio dado a essas empresas para que possam, cada uma a sua medida, contribuir para que as necessidades ou as conveniências do público em geral sejam, de alguma forma, alcançadas (SPÍNOLA, 2003).

Esses dois artigos foram os precursores de uma grande iniciativa governamental para fortalecer a economia nacional por intermédio das micro e pequenas empresas, levando esses agentes a desenvolverem seu papel no "processo de desenvolvimento econômico e social do país". Todo processo de incentivos iniciados pelo governo por intermédio desses dois artigos constitucionais culminou na Lei Complementar (LC) 123/2006, que instituiu o Estatuto Nacional da Microempresa (ME) e da Em- presa de Pequeno Porte (EPP). A Lei Complementar 123/2006 objetivava promover a simplificação e desoneração das atividades desenvolvidas pelas micro e pequenas empresas, restabelecendo preceitos gerais relativos ao tratamento tributário distinto e favorecido a ser dispensado às mesmas, perante um regime de arrecadação unificado, por intermédio do que seria denominado SIMPLES NACIONAL (BRASIL, 2006).

O SIMPLES NACIONAL traçou as obrigações e também os deveres das microempresas, de modo que ficasse claro para os empresários quais benefícios poderiam desfrutar e também qual a contrapartida que deveria oferecer para isso. Um dos pontos de destaque do novo estatuto, conforme já mencionado anteriormente, foi a simplificação proporcionada ao microempresário em amplos aspectos, por exemplo, na questão tributária, administrativa, mercadológica e também em questões de âmbitos estruturais, de acordo com Campos (2009). Segundo o (SEBRAE, 2007):

O SIMPLES NACIONAL foi criado com o objetivo de unificar a arrecadação dos tributos e contribuições devidos pelas micro e pequenas empresas brasileiras, nos âmbitos dos governos federal, estaduais e municipais. O regime especial de arrecadação não é um tributo ou um sistema tributário, mas uma forma de arrecadação unificada dos tributos e contribuições de competência do Estado.

Ainda que esse tenha sido fator de grande evolução para a economia, principalmente no que diz respeito às micro e pequenas empresas, foi diagnosticado que ainda havia possibilidades de aperfeiçoar o sistema, o que se deu com a introdução das Leis Complementares números 127 (BRASIL, 2007) e 128 (BRASIL, 2008), de 14 de agosto de 2007 e 19 de dezembro de 2008, respectivamente.

As Leis Complementares acima citadas implementaram alterações no regime até então vigente que permitiram que os benefícios oferecidos aos adeptos do SIMPLES alcançassem uma maior parcela da população, ofertando uma gama de facilidades ainda maior do que a dos períodos anteriores. O ponto-chave que surgiu a partir da constituição dessas duas novas figuras jurídicas foi a criação de uma nova personalidade jurídica denominada Microempreendedor Individual (MEI), que será tratado na última parte deste estudo. 


\subsection{O Programa Microempreendedor Indivi- dual (MEI)}

O MEI estabelece tratamento tributário diferenciado dentro do Programa do Simples Federal, denominado Sistema de Recolhimento de Valores Fixos Mensais dos Tributos Abrangidos pelo Simples Nacional (SIMEI). Por meio do MEI, o Governo Federal visa atingir a parte da população que exerce alguma forma de atividade profissional economicamente organizada voltada para a produção ou a circulação de bens e/ou serviços que não estava sendo atingida antes pelo SIMPLES NACIONAL, por motivos diversos, tais como evitar as altas tributações que poderiam extinguir o pequeno negócio, falta de conhecimento nos âmbitos burocráticos e outros fatores que viessem a reduzir os ganhos.

$\mathrm{O}$ MEI tem como meta principal reduzir a informalidade no mercado brasileiro, possibilitando ao Governo Federal elevar sua arrecadação com os trabalhadores que hoje aparecem na informalidade e permitir a estes últimos, por sua vez, terem acesso a benefícios que somente os trabalhadores formalizados possuem atualmente. Para atingir essa meta, o programa oferece diversas facilidades e tem um alcance relativamente maior que o SIMPLES, possibilitando que os empresários candidatos à adesão do programa não necessitem ter endereço empresarial fixo, comprovação de renda e não sejam necessariamente obrigados a emitir notas fiscais, embora possam fazê-lo. Ofícios como o de Mágico e Caçador constituem exemplos práticos de profissões que o MEI passa a englobar e que antes deveriam optar por um registro de autônomo ou pela informalidade.

A elevada carga de tributos e a burocracia sempre atuaram como fatores de impedimento para que o cidadão comum que intencionasse iniciar uma nova atividade ou regularizar o seu negócio pudesse se formalizar. Muitas vezes, o trabalhador começava o processo de regulamentação já acumulando débitos que inevitavelmente limitavam suas ambições de formalização. Justamente por ter diagnosticado esse problema, o Governo Federal optou por facilitar ainda mais o SIMPLES e abranger uma camada ainda maior da população, que se formalizaria pagando uma pequena taxa mensal. O Empreendedor Individual (EI) é um profissional que trabalha por conta própria e busca formalização como maneira de al- cançar benefícios oferecidos a outros trabalhadores e também a empresários listados em outras categorias de grande arrecadação, como se segue:

O Empreendedor Individual é a pessoa que trabalha por conta própria e que se legaliza como pequeno empresário. Para ser um empreendedor individual, é necessário faturar no máximo até $\mathrm{R} \$$ $36.000,00$ por ano, não ter participação em outra empresa como sócio ou titular e ter um empregado contratado que receba o salário mínimo ou o piso da categoria (BRASIL, 2011b).

Os optantes pelo MEI deveriam arcar com uma taxa de RS 57,15 para ter acesso a todos os benefícios oferecidos pelo novo regulamento, sendo: $\mathrm{R} \$ 45,65$ para a Previdência Social, mais $\mathrm{R} \$ 5,00$ de Imposto Sobre Serviços (ISS) e R \$ 1,00 de Imposto sobre Circulação de Mercadorias (ICMS). Essa tarifa, que já era relativamente baixa para os empreendedores, foi reduzida ainda mais por meio da Medida Provisória 529/2011 (BRASIL, 2011c), que promoveu a redução da carga tributária dos adeptos do MEI ao alterar a alíquota de contribuição para a previdência social para cinco por cento. Tais medidas visam atrair os pequenos empresários e prestadores de serviços autônomos e informais para aderirem ao MEI e, dessa forma, deixarem a informalidade.

O EI conta com uma série de benefícios que seriam difíceis de acessar na informalidade, tais como: cobertura previdenciária, contratação de um funcionário por um custo reduzido, isenção de taxas para registro de cadastro empresarial, ausência de burocracia, acesso a serviços bancários como o crédito a taxas reduzidas, compras e vendas em conjunto por meio de consórcios específicos, redução da carga tributária, controles simplificados, emissão de alvará pela internet, serviços contábeis gratuitos no primeiro ano, facilidade em possíveis vendas para o governo, apoio técnico do SEBRAE, segurança jurídica e possibilidade de crescimento enquanto empreendedor (BRASIL, 2011b).

Tantos benefícios tornam-se grandes atrativos para que os trabalhadores deixem a informalidade $\mathrm{e}$ passem a atuar como pequenos empresários por meio do programa Microempreendedor Individual. Contudo, para poder aderir ao programa é necessário que os candidatos preencham alguns requisitos, segundo o SEBRAE (2007): 
Considera-se MEI o empresário individual que exerce profissionalmente atividade econômica organizada para a produção ou a circulação de bens ou de serviços, conforme prevê o art. 966 da Lei $\mathrm{n}^{\mathrm{o}} 10.406 / 2002$, e que atenda cumulativamente às seguintes condições:

a) tenha auferido receita bruta acumulada no ano-calendário anterior de até $\mathrm{R} \$ 36.000,00$ (trinta e seis mil reais);

b) seja optante pelo Simples Nacional;

c) exerça tão-somente atividades constantes do tópico XII;

d) possua um único estabelecimento;

e) não participe de outra empresa como titular, sócio ou administrador;

f) não contrate mais de um empregado.

g) no caso de início de atividade, o limite de que trata a alínea "a" será de $\mathrm{R} \$ 3.000,00$ (três mil reais) multiplicados pelo número de meses compreendido entre o início da atividade e o final do respectivo ano-calendário, consideradas as frações de meses como um mês inteiro ${ }^{6}$.

Basicamente, as normas citadas impõem ao EI um limite em suas atividades, colocando em regras claras até onde suas atividades podem chegar e em troca oferecem a ele a possibilidade de crescer junto com seu negócio de forma legalizada, acessando direitos e benefícios mencionados.

A vantagem de aderir ao MEI em comparação com a condição de informal é clara e visível, sendo o leque de possibilidades do EI muito mais amplo que o de um trabalhador informal. Em relação aos autônomos, o EI tem a vantagem de ser isento de pagamento da Taxa de Licença e possui o benefício de uma contribuição previdenciária menor que o primeiro.

Além de todos os benefícios já citados, o MEI ainda possui a facilidade de poder fazer tudo da própria casa, usando o Portal do Empreendedor. O interessado deve, antes de qualquer coisa, consultar a Prefeitura da cidade onde deseja se cadastrar como EI para saber quais são as restrições impostas pela

\footnotetext{
${ }^{6}$ Fundamentação: art. 18-A, $\$ 11^{\circ}$ da Lei Complementar n 123/2006; art. 1\%, $\S \S 1^{\circ}$ e $2^{\circ}$ da Resolução CGSN no 58/2009.
}

legislação local. Tendo conhecimento da atividade que deseja exercer, o empreendedor, de forma bastante simplificada, necessita ter seus documentos pessoais em mãos e os dados do endereço onde deseja que o seu negócio funcione, podendo este ser sua própria residência, para efetuar o cadastro no site, no link denominado "formalize-se agora". O interessado pode ainda optar por fazer sua inscrição nos escritórios de contabilidade e entidades de classe credenciadas para cadastrar os empreendedores individuais.

O MEI já começa a apresentar resultados positivos em sua missão de reduzir a informalidade no país, de acordo com Brasil (2011d):

De acordo com dados de 8 de maio, 1.119 .730 pessoas já se cadastraram pelo portal www.portaldoempreendedor.com.br. Desse número, 32\% estão localizadas nas capitais. Em 98,7\% dos municípios brasileiros (5.491), há pelo menos um Empreendedor Individual cadastrado em uma das 467 atividades econômicas possíveis. Isso reflete a potencialidade de expansão do programa, principalmente para os municípios de pequeno e médio porte.

As cidades com maior índice de adesão ao programa são: São Paulo (SP), com 70.913 inscritos; Rio de Janeiro (RJ), com 56.164; Salvador (BA), com 36.268; Belo Horizonte (MG), com 20.758; e Brasília (DF), com 20.618. Já os Estados com mais cadastramento são: São Paulo (239.572), Rio de Janeiro (145.921), Minas Gerais (109.593), Bahia (100.290) e Rio Grande do Sul (62.246).

Entre as atividades econômicas, o destaque é para o comércio varejista de artigos do vestuário e acessórios (113.289); cabeleireiros (82.947); lanchonetes, casas de chá, de sucos e similares (35.145); minimercados, mercearias e armazéns (34.254); e bares (30.505). A meta do governo é registrar 1,5 milhões de trabalhadores até o final do ano.

A referida pesquisa vem somente mostrar o potencial do MEI como ferramenta a ser utilizada para a redução do emprego informal no Brasil e não somente deste, como também das taxas de desemprego, já que oferece uma nova possibilidade para aqueles que estão fora do mercado de trabalho.

O Governo, em suas várias esferas, espera que, por meio das facilidades oferecidas para adesão ao programa, das várias possibilidades de ofício para que o cidadão/empreendedor faça seu cadastro no EI, das semanas do Empreendedor que vêm sendo 
promovidas pelo SEBRAE e ainda da grande divulgação dos meios de comunicação, a informação necessária alcance as grandes massas e consiga incentivar os trabalhadores informais a aderirem ao MEI, estimulando outros cidadãos a abrirem seus negócios como empresários individuais.

\section{Considerações Finais}

O Brasil vem adotando medidas no sentido de reduzir o trabalho informal no país, que é um dos maiores do mundo, a fim de garantir maior segurança aos trabalhadores ao passo que aumenta sua arrecadação tributária, almejando mais recursos para investir em seu crescimento econômico. Neste artigo, foi feita uma análise do programa Microempreendedor Individual (MEI), começando por uma apresentação dos preceitos constitucionais que previam o benefício aos pequenos empresários, chegando ao SIMPLES, que foi um mecanismo que proporcionou enorme evolução para as micro e pequenas empresas.

O MEI oferece benefícios aos interessados para que se formalizem e passem a usufruir de direitos que os empresários formais desfrutam, e tenham seu trabalho, objeto de seu sustento, legalizado. Posteriormente à legalização e ao desenvolvimento do empreendimento, o microempreendedor pode até mesmo ampliar seu negócio passando, então, a ser agente de desenvolvimento regional, criando novos postos de trabalho.

A atuação do governo no desenvolvimento do programa, como agente de redução da informalidade, vem sendo bem-sucedida, como observado na pesquisa realizada pelo Ministério do Desenvolvimento, Indústria e Comércio Exterior realizada em maio de 2011, na qual foi mostrado o avanço do número de cadastrados no programa (Brasil, 2011d).

Pode-se concluir, portanto, que o MEI, trilhando o caminho que vem seguindo atualmente, poderá ser agente significativo de mudança na economia nacional e representará ao Estado uma maior arrecadação e aos empreendedores mais estabilidade financeira a partir de um melhor alcance dos seus direitos, além de vantagens comparativas no mercado competitivo.

\section{Referências}

BRASIL. Constituição da República Federativa do Brasil: promulgada em 5 de outubro de 1988. Organização do texto: Juarez de Oliveira. 4. ed. São Paulo: Saraiva, 1990. 168 p. (Série Legislação Brasileira).

BRASIL. Diário Oficial da União. Lei Complementar $\mathbf{n}^{\circ}$ 123/06, de 14 de dezembro de 2006. Institui o Estatuto Nacional da Microempresa e da Empresa de Pequeno Porte e dá outras providências. Disponível em: <http://migre. $\underline{\mathrm{me} / 5 \mathrm{q} 2 \mathrm{rD}}>$. Acesso em: 15 de jun. de 2011.

BRASIL. Lei Complementar $n^{\circ} \mathbf{1 2 7}$, de 14 de agosto de 2007. Altera a Lei Complementar $n^{\circ} 123$, de 14 de dezembro de 2006. Disponível em: <http://migre.me/5z9um $>$. Acesso em: 25 de jul. de 2011.

BRASIL. Lei $\mathbf{n}^{\mathbf{1}} \mathbf{1 2 8 / 0 8}$, de 19 de dezembro de 2008. Altera a Lei Complementar $\mathrm{n}^{\circ} 123$, de 14 de dezembro de 2006, altera as Leis $\mathrm{n}^{\circ} 8.212$, de 24 de julho de 1991, $\mathrm{n}^{\circ} 8.213$, de 24 de julho de 1991, $\mathrm{n}^{\mathrm{o}} 10.406$, de 10 de janeiro de 2002 - Código Civil, 8.029, de 12 de abril de 1990, e dá outras providências. Disponível em: <http://migre.me $/ 5 \mathrm{z} 91 \mathrm{~F}>$. Acesso em: 25 de jul. de 2011.

BRASIL. Ministério das Relações Exteriores. BRICS Agrupamento Brasil-Rússia-Índia-China-África do Sul. 2011a. Disponível em: <http://migre.me/5AsyK $>$. Acesso em: 07 de ago. de 2011.

BRASIL. Ministério da Fazenda. Características do Simples Nacional. 2011b. Disponível em: <http://migre. $\underline{\mathrm{me} / 5 \mathrm{q} 2 \mathrm{sC}}>$.Acesso em: 10 de jun. de 2011.

BRASIL. Medida Provisória $\mathbf{n}^{\mathbf{0}}$ 529, de 7 de Abril de 2011c. Altera a Lei no 8.212, de 24 de julho de 1991, no tocante à contribuição previdenciária do microempreendedor individual. Disponível em: <http://migre.me/5z9Zy $>$. Acesso em: 30 de jul. de 2011.

BRASIL. Ministério do Desenvolvimento, Indústria e Comércio Exterior. Governo pede apoio dos prefeitos para fortalecer empreendedor individual nos municípios. 2011d. Disponível em: <http://migre.me/5q2Hn $>$. Acesso em: 29 de mai. de 2011.

CAMPOS, M. H. S. O "SIMPLES NACIONAL" como imposto único incidente sobre a renda e consumo das microempresas e das empresas de pequeno porte no Brasil. 2009. Disponível em: <http://migre.me/5z98x $>$. Acesso em: 13 de ago. de 2011.

HURRELL, A. Os BRICs e a Ordem Global. Rio de Janeiro: FGV Editora, 2009.

IBGE. Pesquisa Nacional por Amostra de Domicílios. 2009.

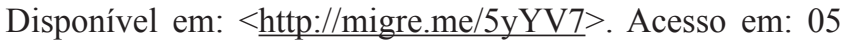
de ago. de 2011.

MCKINSEY \& COMPANY. Eliminando as Barreiras ao Crescimento Econômico e à Economia Formal no Brasil. 
São Paulo, Junho de 2004. Disponível em: $<$ http://migre. me/7aaSW>. Acesso em: 10 de set. de 2011.

O'NEILL J. Building Better Global Economic BRICs; 2001. Disponível em: $<$ http://migre.me/5q2te $>$. Acesso em: 15 de mai. de 2011.

POCHMANN M. et al. Características da formalização do mercado de trabalho brasileiro entre 2001 e 2009. Brasília: IPEA, 2011. Disponível em: <http://migre. me/5yYAf $>$. Acesso em: 19 de jun. de 2011.

RÊGO, J. A. P. B. A Reputação do Brasil. 2008. Disponível em: $<$ http://migre.me/5q2uc $>$. Acesso em: 02 de jul. de 2011.

SEBRAE. Lei Geral da Micro e Pequena Empresa. Brasília: 2007.

SPÍNOLA, A. S. O tratamento diferenciado, simplificado e favorecido concedido à microempresa e à empresa de pequeno porte. 2003. Disponível em: $<$ http://migre. me/5q2wt> . Acesso em: 24 de jul. de 2011.

UnB. Informais evitam registro para fugir dos impostos. 2010. Disponível em: $<$ http://migre.me/5z7hS $>$. Acesso em: 22 de ago. de 2011.

Recebido em 30 de julho de 2013.

Aceito em 14 de outubro de 2013. 